\title{
In vivo evaluation of tumour acidosis for assessing the early metabolic response and onset of resistance to dichloroacetate by using magnetic resonance $\mathrm{pH}$ imaging
}

\author{
ANNASOFIA ANEMONE ${ }^{1}$, LORENA CONSOLINO ${ }^{1}$, LAURA CONTI $^{1}$, FRANCESCA REINERI $^{1}$, \\ FEDERICA CAVALLO $^{1}$, SILVIO AIME ${ }^{1}$ and DARIO LIVIO LONGO ${ }^{2}$ \\ ${ }^{1}$ Department of Molecular Biotechnology and Health Sciences, University of Turin; ${ }^{2}$ National Research Council \\ of Italy (CNR), Institute of Biostructure and Bioimaging, Molecular Imaging Center, 10126 Turin, Italy
}

Received November 24, 2016; Accepted May 15, 2017

DOI: $10.3892 /$ ijo.2017.4029

\begin{abstract}
Dichloroacetate (DCA) can reverse the glycolytic phenotype that is responsible of increased lactate production and extracellular $\mathrm{pH}$ acidification in cancer cells. Magnetic resonance imaging-chemical exchange saturation transfer (MRI-CEST) $\mathrm{pH}$ mapping is a novel non-invasive imaging approach that can measure in vivo extracellular tumour $\mathrm{pH}$. We examined whether MRI-CEST $\mathrm{pH}$ mapping can monitor in vivo changes in tumour acidosis for assessing treatment response to DCA. Cell viability and extracellular $\mathrm{pH}$ were assessed in TS/A breast cancer cells treated with 1-10 mM DCA for $24 \mathrm{~h}$ in normoxia or hypoxia $\left(1 \% \mathrm{O}_{2}\right)$ conditions. Extracellular tumour $\mathrm{pH}$ values were measured in vivo by MRI-CEST $\mathrm{pH}$ mapping of TS/A tumour-bearing mice before, three days and fifteen days after DCA or saline treatment. Reduced extracellular acidification and vitality were observed in DCA-treated TS/A cells. Tumour-bearing mice showed a marked and significant increase of tumour extracellular $\mathrm{pH}$ at 3 days post-DCA treatment, reflecting DCA-induced glycolysis inhibition, as confirmed by reduced lactate production. After 15 days of DCA treatment, the onset of resistance to DCA was observed, with recover of tumour extracellular acidification and lactate levels that returned to baseline values. A significant correlation was observed between tumour extracellular $\mathrm{pH}$ values and lactate levels $(\mathrm{r}=-0.97, \mathrm{P}<0.05)$. These results suggest that MRI-CEST $\mathrm{pH}$ imaging is a promising tool to monitor the early response and efficacy of cancer metabolic targeting drugs.
\end{abstract}

Correspondence to: Dr Dario Livio Longo, National Research Council of Italy (CNR), Institute of Biostructure and Bioimaging, c/o Molecular Imaging Center, Via Nizza 52, 10126 Torino, Italy E-mail: dario.longo@unito.it

Key words: metabolism, dichloroacetate, MRI-CEST, breast cancer, tumour extracellular $\mathrm{pH}$

\section{Introduction}

It is well known that the extracellular $\mathrm{pH}(\mathrm{pHe})$ within the microenvironment of tumours is significantly lower (more acidic) compared with that of normal tissues (1). Although several factors play a role in the acidification process, it is well accepted that the major contribution arises from a shift in the ATP generation; according to the Warburg effect, ATP is produced via aerobic glycolysis even in presence of oxygen (2). In this contest, poor vascularisation and increased activity of plasma membrane ion pumps and transporters $\left(\mathrm{H}^{+}\right.$-ATPases, the $\mathrm{Na}^{+}-\mathrm{H}^{+}$exchanger NHE1 and the monocarboxylate$\mathrm{H}^{+}$efflux co-transporters MCT1 and MCT4) contribute to the extracellular acidification of most, but not all tumours (3). Many studies on solid tumours and in particular on breast tumours suggested that a glycolytic environment is related not only to uncontrolled proliferation and evasion of apoptosis induction, but also to the expansion through the extra-cellular matrix, the increase of the metastatic potential and the promotion of angiogenesis (4). Therefore, novel drugs addressing specific aspects of the deregulated tumour metabolism have been proposed for inhibiting tumour growth and survival.

Dichloroacetate (DCA), a mitochondria-targeting small molecule of 150 Da used to treat lactic acidosis, can reverse this cancer-specific metabolic remodelling (5). DCA inhibits pyruvate dehydrogenase kinase (PDK) whose expression is high in many cancers, causing pyruvate conversion into lactate (6). DCA-mediated inhibition of PDK re-establishes metabolism of pyruvate into the tricarboxylic acid cycle and decreases the lactate accumulation and production. Thus, DCA increases the glucose oxidation therefore promoting apoptosis and blocking tumour proliferation $(7,8)$. Several clinical studies tested the DCA antitumour efficacy and its safety in patients with advanced solid tumours (9). Overall, these studies reported that oral DCA is well tolerated and safe, it reduces lactate levels and it can act as an apoptosis sensitizer in combination with cytotoxic treatments.

Despite the specific mechanism of action of DCA on tumour glycolysis, tumour response to DCA treatment has conventionally been assessed through simple measurements of changes in tumour size by using morphological imaging techniques such 
as magnetic resonance imaging (MRI) or computed tomography (CT). However, the assessment of changes in tumour volume does not provide indications on tumour acidosis variations induced by metabolism-targeting drugs. Several MRI methods have been proposed for non-invasive measurements of in vivo tumour $\mathrm{pH}(10)$. In particular, ${ }^{31} \mathrm{P}$-magnetic resonance spectroscopy $\left({ }^{31} \mathrm{P}-\mathrm{MRS}\right)$ allows measuring intracellular and extracellular $\mathrm{pH}$ changes from the chemical shift of endogenous phosphate or of exogenous agents, but with poor spatial resolution (11). Gd-based contrast agents that exhibit a $\mathrm{pH}$-dependent relaxivity have been exploited for measuring tumour $\mathrm{pH}$ in a rat glioma model, but a limitation of this approach is related to the need of injecting two Gd-based contrast agents for accurate $\mathrm{pH}$ measurements (12). Hyperpolarized ${ }^{13} \mathrm{C}$-bicarbonate can provide pHe map with high sensitivity (13), while several hyperpolarised molecules can provide insight into metabolism in both cells and animals (14-18). However, this technique is expensive, limited by low spatial resolution and requires sophisticated instrumentations that are not easily available in the clinical setting.

Recently, chemical exchange saturation transfer (CEST) imaging has been proposed as a novel MRI-based technique and several agents have been considered for assessing tumour metabolism and pHe (19-23). Among them, clinical approved radiographic contrast agents and heterocyclic compounds have been exploited for measuring $\mathrm{pH}$ and pathologicalinduced $\mathrm{pH}$ changes (24-28). In addition, MRI-CEST $\mathrm{pH}$ mapping was demonstrated to be an excellent tool to investigate the relationship between glycolysis and acidosis at clinical magnetic field (29).

In this study, we investigated whether DCA-induced changes in metabolism and tumour acidosis in a murine breast cancer model can be monitored non-invasively by MRI-CEST $\mathrm{pH}$ mapping.

\section{Materials and methods}

Cell culture. TS/A cells, derived from a spontaneous BALB/c mammary tumour, were grown in RPMI-1640 medium supplemented with $10 \%$ fetal bovine serum (FBS), $100 \mathrm{U} / \mathrm{ml}$ penicillin and $100 \mu \mathrm{g} / \mathrm{ml}$ streptomycin (Pen/Strep) and $2 \mathrm{mM}$ L-glutamine (30). 4T1 cells, a BALB/c-derived mouse mammary carcinoma corresponding to stage IV of human breast cancer, were purchased from American Type Culture Collection (ATCC LGC Standards, Sesto San Giovanni, Italy) and cultured as TS/A cells. TUBO cells were derived from a lobular carcinoma arising spontaneously in a BALB-neuT mouse and were grown in DMEM medium supplemented with $20 \%$ FBS and Pen/Strep (31).

J774 non-tumour cell line (purchased from ATCC) was grown in DMEM medium supplemented with $10 \%$ FBS, Pen/Strep and L-glutamine. All the cell lines were cultured in a humidified atmosphere $\left(37^{\circ} \mathrm{C}, 5 \% \mathrm{CO}_{2}\right)$.

Cell vitality test. The cytotoxic effect of DCA (Sigma-Aldrich, St. Louis, MO, USA) on cells was analysed with the CellTiterBlue Cell Viability Assay (Promega Corp., Madison, WI, USA). Briefly, TS/A $\left(5 \times 10^{3}\right)$ cells were plated in 96-well culture plates and after $24 \mathrm{~h}$ of incubation were treated with DCA $(1,5$ and $10 \mathrm{mM})$ for $24 \mathrm{~h}$. The non-tumour cell line $\mathrm{J} 774\left(30 \times 10^{3}\right)$ was used as control and treated in the same way. Afterwards, cells were washed with PBS and then CellTiter-Blue reagent was added to each well. Fluorescence was measured at 560Ex/590Em using a 96-well plate reader. Each assay was repeated at least three times.

pH measurement in normoxia and hypoxia condition. TS/A cells were seeded in $60-\mathrm{mm}$ culture dish with a final volume of $3 \mathrm{ml}$ at a density of $4 \times 10^{5}$ cells. After $24 \mathrm{~h}$ of incubation in $20 \% \mathrm{O}_{2}$ (normoxia) or $1 \% \mathrm{O}_{2}$ (hypoxia) (New Brunswick ${ }^{\mathrm{TM}}$ Galaxy ${ }^{\circledR} 48$ R, Eppendorf S.r.1., Milan, Italy) cells were treated with a solution of DCA $(1,5$ and $10 \mathrm{mM})$ and kept in the culture medium for additional $24 \mathrm{~h}$. Then the culture medium was collected and the $\mathrm{pH}$ was immediately measured using a pH meter (Hamilton ${ }^{\circledR}$ Slim Trode, GR, Switzerland) previously calibrated. The non-tumour cell line J774 underwent the same procedure. Each experiment was performed in triplicate.

FACS analysis. The cell cycle perturbations were analysed by propidium iodide (PI) DNA staining. TS/A cells $\left(5 \times 10^{5}\right)$ were treated with DCA $(1,5$ and $10 \mathrm{mM})$ for $24 \mathrm{~h}$. At the end of each treatment, cells were collected after a centrifugation (200 x g, $5 \mathrm{~min})$ and then fixed in ethanol (70\%, $3 \mathrm{~min}, 4^{\circ} \mathrm{C}$ ). Ethanol-suspended cells were diluted with phosphate buffered saline (PBS) and then centrifuged to remove residual ethanol (471 x g, $5 \mathrm{~min}$ ). For cell cycle analysis, the pellets were suspended in $0.1 \mathrm{ml}$ of PBS containing $50 \mu \mathrm{g} / \mathrm{ml}$ of PI, $100 \mu \mathrm{g} /$ $\mathrm{ml}$ of RNase A and $0.05 \%$ of Triton X-100 and incubated at $37^{\circ} \mathrm{C}$ for 40 minutes. Cell cycle profiles were studied using a CyanADP flow cytometer and analysed with Summit 3.4 software (Beckman Coulter, Milano, Italy) and BD FACSuite software (Becton Dickinson, Milano, Italy). Each assay was repeated a minimum of three times.

Animal experiments. BALB/c female mice (Charles River Laboratories Italia S.r.l., Calco, Italy) were maintained in the animal facility of the Dept. Molecular Biotechnology and Health Sciences, University of Turin, under specific pathogen-free conditions. All animal studies were approved by the University Ethics Committee in accordance with the European guidelines under directive 2010/63.

Mice were inoculated subcutaneously with $2.5 \times 10^{5} \mathrm{TS} / \mathrm{A}$ mammary adenocarcinoma cells on both flanks. When the tumours were approximately $60 \mathrm{~mm}^{3}$, TS/A tumour-bearing mice were randomly divided in two groups: untreated group that received drinking water and intraperitoneal injections of PBS, and DCA-treated group that received DCA by oral administration of $0.45 \mathrm{~g} / \mathrm{l}(100 \mathrm{mg} / \mathrm{kg} /$ day $)$ and also by intraperitoneal injections of $50 \mathrm{~g} / 1(200 \mathrm{mg} / \mathrm{kg} / \mathrm{day})$ (32). DCA or PBS solutions were administered every day after baseline measurements. All mice were scanned at day 0 (untreated $\mathrm{n}=10$ mice, treated $\mathrm{n}=8$ mice), 3 days (untreated $\mathrm{n}=10$ mice, treated $n=8$ mice) and 15 days (untreated $n=7$ mice, treated $\mathrm{n}=5$ mice) post-treatment. At each time point post-treatment, three mice per group were sacrificed and tumour tissues were excised for lactate level quantification.

For MRI acquisition mice were anesthetized and the breath rate was monitored by an air pillow placed below the animal (SA Instruments, Stony Brook, NY, USA). MRI-CEST pH 

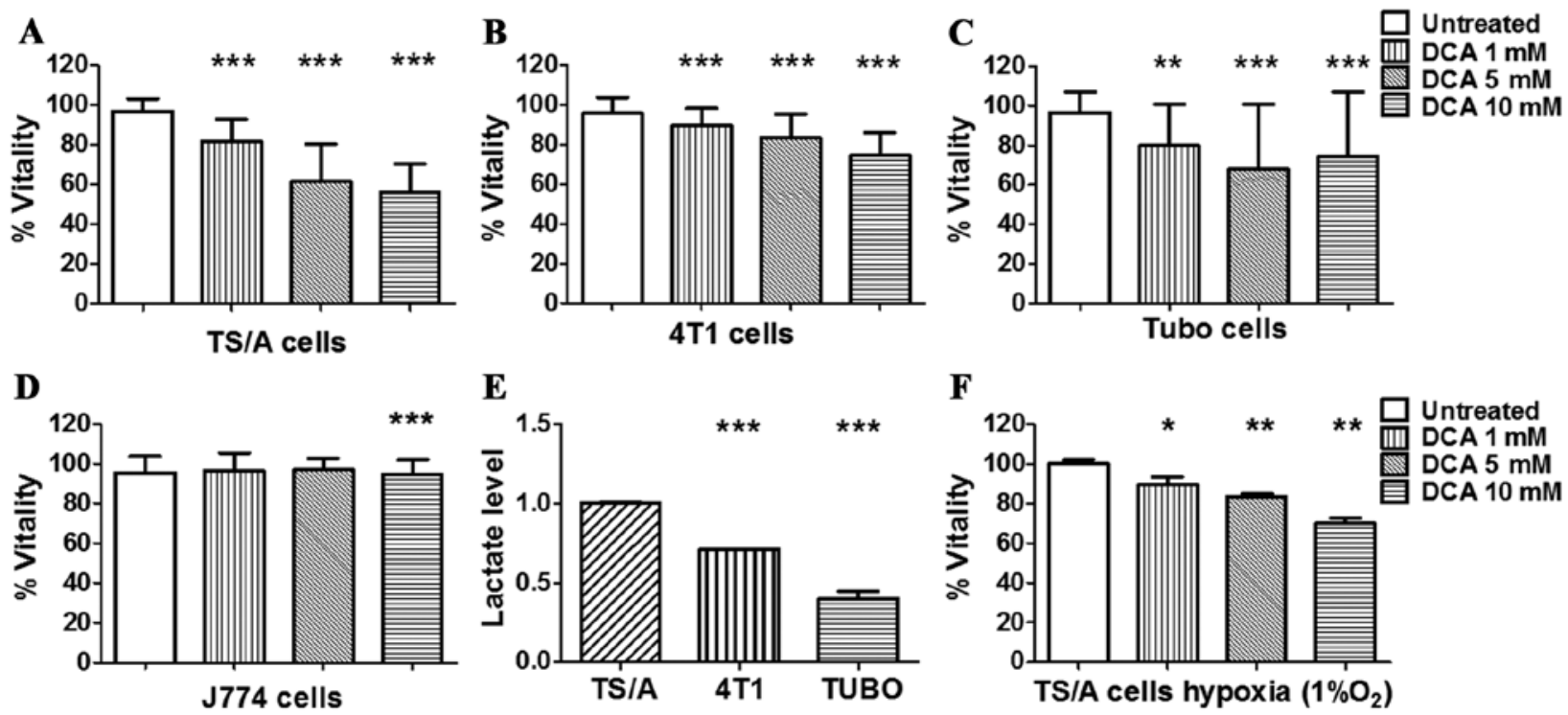

Figure 1. In vitro efficacy of DCA on breast cancer cell lines. Percentage of vitality of TS/A cultured in normoxic (A) and hypoxic condition (F), and of 4T1 (B), TUBO (C) and non-tumour control cell line J774 (D) cells after $24 \mathrm{~h}$ of DCA treatment in normoxic condition. Culture medium extracellular lactate levels in normoxic conditions for TS/A, 4T1 and TUBO (E). ${ }^{*} \mathrm{P}<0.05 ;{ }^{* *} \mathrm{P}<0.01 ;{ }^{* * *} \mathrm{P}<0.001$, Dunnett's multiple comparison test.

mapping was performed upon i.v. injection of $4 \mathrm{~g} \mathrm{I} / \mathrm{kg}$ b.w. iopamidol (Bracco Imaging SpA, Colleretto Giacosa, Italy) into the tail vein through a 27 -gauge needle.

MRI CEST pH-mapping acquisition and analysis. MR images were acquired with a Bruker 7T Avance 300 MRI scanner (Bruker Biospin, Ettlingen, Germany) equipped with a 30-mm $1 \mathrm{H}$ birdcage coil before starting the treatment, after 3 and 15 days of treatment.

Anatomical $\mathrm{T}_{2 \mathrm{w}}$ images were acquired with a Fast Spin Echo (FSE) sequence and the same geometry was used for the following CEST experiments. CEST images were acquired before and after iopamidol i.v. injection with a single shot FSE sequence with centric encoding preceded by a continuouswave saturation pulse (power: $3 \mu \mathrm{T}$, duration: $5 \mathrm{sec}$ ) on a central tumour slice (field-of-view: $3 \mathrm{~cm}$, matrix: 128x128, in-plane resolution: $234 \mu \mathrm{m}$, slice thickness: $1.5 \mathrm{~mm}$ ). CEST images were analysed using homemade MATLAB scripts (Mathworks, Inc., Natick, MA, USA). Briefly, saturation transfer effects were calculated upon irradiating at 4.2 and at $5.5 \mathrm{ppm}$, respectively, and post-contrast ST maps were subtracted to pre-contrast ST ones, to obtain the corresponding ST contrast difference $(\Delta \mathrm{ST})$ maps. The pixel-by-pixel extracellular $\mathrm{pH}(\mathrm{pHe})$ maps were calculated using the ratio between the two contrast difference maps at 4.2 and $5.5 \mathrm{ppm}$ according to the previously described method (24). The calculated pHe maps were superimposed to the anatomical reference image.

A novel estimate, dubbed acidity score, was calculated for taking into account the heterogeneity of $\mathrm{pHe}$ distribution values within the tumour region. The tumour pixels were clustered into three groups: group I for pixels showing $\mathrm{pHe}$ values $>7.0$, group II for pixels showing $\mathrm{pHe}$ values $>6.7$ and $<7.0$, group III for pixels showing pHe values $<6.7$. The percentage of pixels of each group was multiplied by a factor between 1 and 3, to obtain the acidity score, in accordance to the equation:

Acidity Score $=\{[1 \times(\%$ of pixels with $p H e>7.0)]+[2 \times(\%$ of pixels with 6.7 $<$ pHe $<7.0)]+[3 \times(\%$ of pixels with $p H e<6.7)]\}$
The acidity score ranges from 1 (less acidic) to 3 (more acidic), describing tumour regions with different acidosis levels.

Survival curves. A second cohort of female BALB/c mice was inoculated with $2.5 \times 10^{5} \mathrm{TS} / \mathrm{A}$ cells into the right flank for long-term effect following DCA treatment. After the tumour reached $1 \mathrm{~mm}$ mean diameter, animals were randomized into two groups: untreated $(n=9$ mice) and DCA-treated $(n=11$ mice). DCA-treated group received DCA by oral administration $(100 \mathrm{mg} / \mathrm{kg} / \mathrm{day})$ and also by intraperitoneal injection (200 mg/kg/day) every day. Untreated group received equal volumes of PBS. Mice were monitored every day and volumes were measured using a calliper and calculated from orthogonal measurements of external dimensions as (width ${ }^{2} \mathrm{x}$ length)/2. Mice were euthanized when tumour volume reached values around $600 \mathrm{~mm}^{3}$.

Lactate assay. TS/A cells were seeded in 60-mm culture dish with a final volume of $3 \mathrm{ml}$ and incubated under standard cell culture condition overnight for $24 \mathrm{~h}$. Thereafter, cells were treated with DCA for $24 \mathrm{~h}$ and culture media was collected and tested for lactate level following the manufacturer's instructions of Lactate assay kit (MAK064 Sigma-Aldrich, St. Louis, MO, USA).

After MRI acquisition, three mice per each time point and group were sacrificed and tumour tissues were excised and frozen in liquid nitrogen. Tumour tissue was explanted after animal sacrifice and it was frozen in liquid nitrogen. Tumour was then homogenized on ice in 4 volumes of lactate assay buffer; the sample was centrifuged at $13.000 \mathrm{x} \mathrm{g}$ for $10 \mathrm{~min}$ to remove insoluble material and deproteinized with a $10 \mathrm{kDa}$ MWCO spin filter to remove endogenous lactate dehydrogenase. The soluble fraction was then assayed by Lactate assay kit.

Statistical analysis. Calculations were performed using GraphPad Prism (GraphPad Software, La Jolla, CA, USA) 

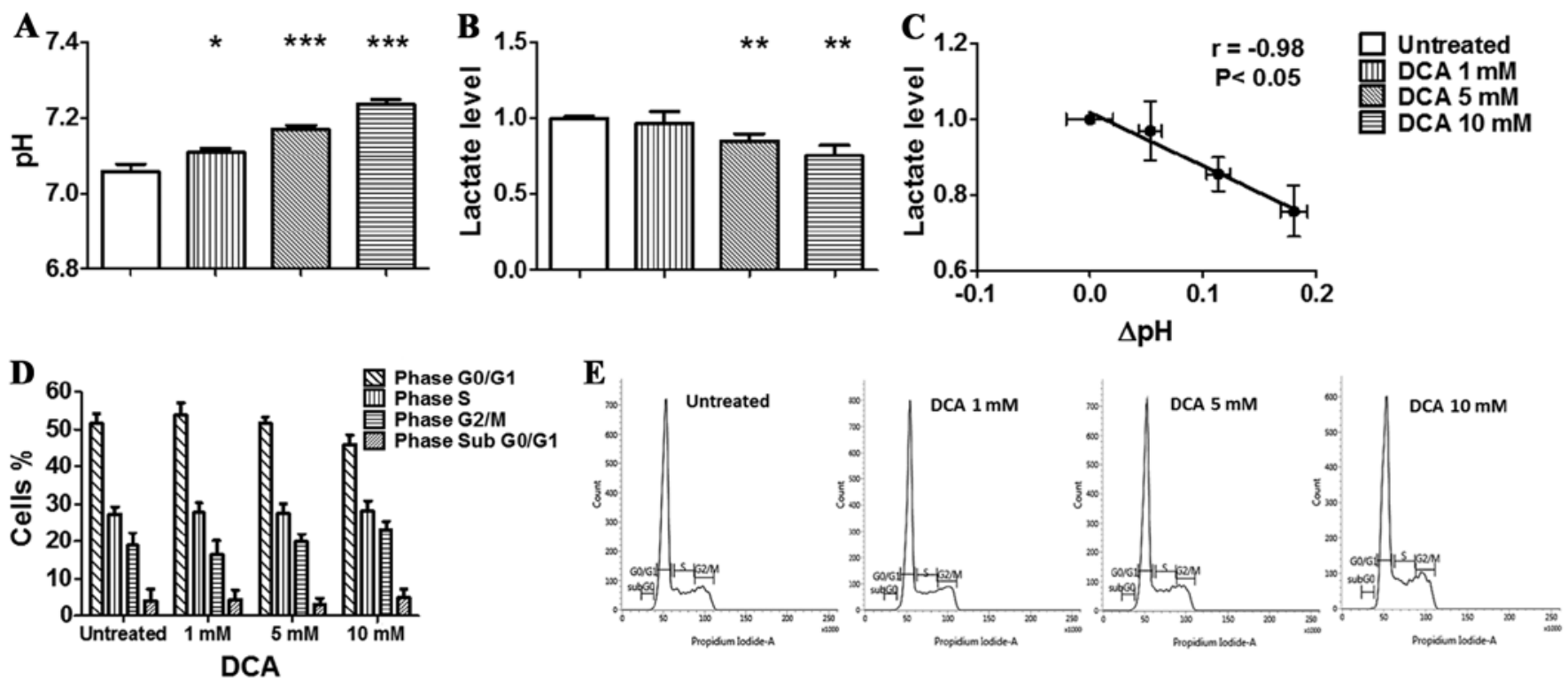

Figure 2. In vitro efficacy of DCA on TS/A acidification and cell cycle progression. Culture medium $\mathrm{pH}$ (A) and extracellular lactate level (B) measurements after $24 \mathrm{~h}$ of DCA treatment for TS/A cells grown in normoxic $\left(20 \% \mathrm{O}_{2}\right)$ conditions. Correlation between changes in lactate levels and extracellular pH measured in the culture medium (Pearson's $\mathrm{r}=-0.98, \mathrm{P}<0.05, \mathrm{C}$ ). (D and E) Cell cycle distribution of TS/A cells treated with different doses of DCA for $24 \mathrm{~h}$ analyzed by flow cytometry after propidium iodide staining. (D) Bar graph showing the percentage of cells in the different phases of cell cycle (from three independent experiments, mean \pm SEM) and (E) representative flow cytometer histograms. ${ }^{*} \mathrm{P}<0.05 ;{ }^{* *} \mathrm{P}<0.01 ;{ }^{* * *} \mathrm{P}<0.001$, Dunnett's multiple comparison test.

software package. Significance between DCA-treated and control groups was determined by one-way analysis of variance, followed by post-hoc tests with the Dunnett's multiple comparison test. Correlation analysis was performed using Pearson's $r$ correlation coefficient. Data are presented as mean \pm SD unless otherwise stated. Statistical significance was established at $\mathrm{P}<0.05$.

\section{Results}

DCA metabolic inhibition impairs TS/A proliferation but not the cell cycle. In order to investigate the metabolic inhibition efficiency of DCA, a panel of breast cancer cell lines was treated with several concentrations of DCA for $24 \mathrm{~h}$ under normoxia condition. As shown in Fig. 1, after $24 \mathrm{~h}$ of treatment, TS/A, 4T1 and TUBO cancer cell lines showed a reduction in their metabolic capacity even at low concentration, whereas the non-tumour J774 control cell line was not affected (Fig. 1D). The response of TS/A breast cancer after $24 \mathrm{~h}$ of DCA treatment was dose-dependent (Fig. 1A) and a significant reduction of cell vitality was already observed at 5 mM DCA concentration.

Furthermore, compared to the other cell lines, untreated TS/A cells produced significantly higher level of lactate (Fig. 1E), hence reflecting a more glycolytic phenotype that could explain their higher sensitivity to DCA treatment. On the basis of these observations, TS/A cell line was selected for subsequent in vitro and in vivo studies.

DCA effect was also investigated under hypoxia $\left(1 \% \mathrm{O}_{2}\right)$ to mimic in vivo tumour hypoxic conditions. A significant decrease in TS/A vitality was observed for all the investigated DCA concentrations, compared to untreated cells (Fig. 1F).

In order to verify if the effect exerted by DCA on cancer cell vitality was due to a perturbation of their cell cycle, as reported for glioblastoma, glioma, non-small cell lung cancer and other cancer cell lines (33-36), TS/A cells were incubated with DCA for $24 \mathrm{~h}$, then stained with PI and analysed by flow cytometry. As shown in the graph (Fig. 2D) and in the representative histograms reported in Fig. 2E, DCA did not affect the cell cycle of TS/A cells, although the amount of cells in the $\mathrm{G} 1 / \mathrm{G} 0$ phase decreased from $51.6 \%$ (untreated cells) to $45.9 \%$ in the presence of $10 \mathrm{mM}$ DCA while cells in G2/M phase increased from $18.8 \%$ (untreated cells) to $23.1 \%$. The amount of TS/A cells in the S phase did not change between untreated and treated with $10 \mathrm{mM}$ of DCA. Moreover, the percentage of hypodiploid cells undergoing apoptosisinduced DNA fragmentation, represented by the sub-G1/G0 population, was very low in all the conditions analysed, and was not increased by DCA treatment. These data suggest that DCA can affect cell vitality through different mechanisms in different types of tumours, mainly acting as a metabolic agent.

DCA promotes extracellular $p H$ alkalinisation in both normoxia and hypoxia conditions. Treatment of TS/A cells for $24 \mathrm{~h}$ in normoxic condition (Fig. 2A) resulted in a moderate but significant and constant increase of culture medium $\mathrm{pH}$ values (from $7.06 \pm 0.02$ to $7.23 \pm 0.01$ ) with increasing DCA concentrations. The increase of pHe was significantly more pronounced in the hypoxic condition (Fig. 3A) than in the normoxic condition. In fact, hypoxic condition resulted in lower $\mathrm{pH}$ of the culture medium for untreated TS/A cells in comparison to normoxic condition ( $\mathrm{pHe}=6.78 \pm 0.02$ ). Moreover, DCA treatment resulted in an even higher increase of pHe up to $7.53 \pm 0.01(\mathrm{P}<0.001)$. The measured increase in extracellular $\mathrm{pH}$ displayed by TS/A cells after treatment is linked to the DCA-induced switch from glycolytic to more oxidative phenotype as evidenced by decreased lactate 

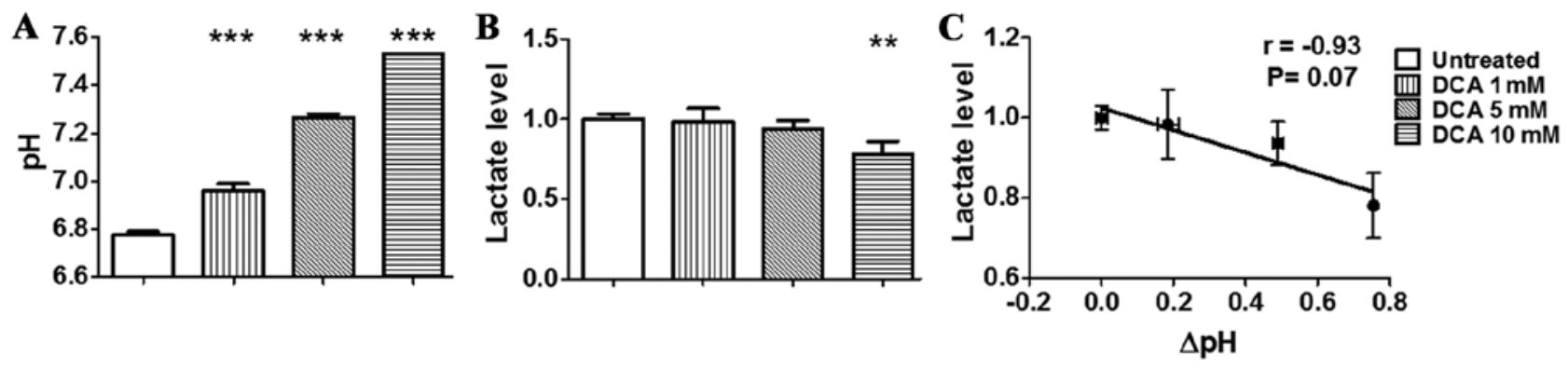

Figure 3. In vitro efficacy of DCA on TS/A acidification in hypoxic condition. Culture medium $\mathrm{pH}$ (A) and extracellular lactate level (B) measurements after $24 \mathrm{~h}$ of DCA treatment for TS/A cells grown in hypoxic $\left(1 \% \mathrm{O}_{2}\right)$ conditions. Correlation between changes in lactate levels and extracellular $\mathrm{pH}$ measured in the culture medium (Pearson's $\mathrm{r}=-0.93, \mathrm{P}=0.07, \mathrm{C}) .{ }^{*} \mathrm{P}<0.05 ;{ }^{* * *} \mathrm{P}<0.01 ;{ }^{* * * *} \mathrm{P}<0.001$, Dunnett's multiple comparison test.

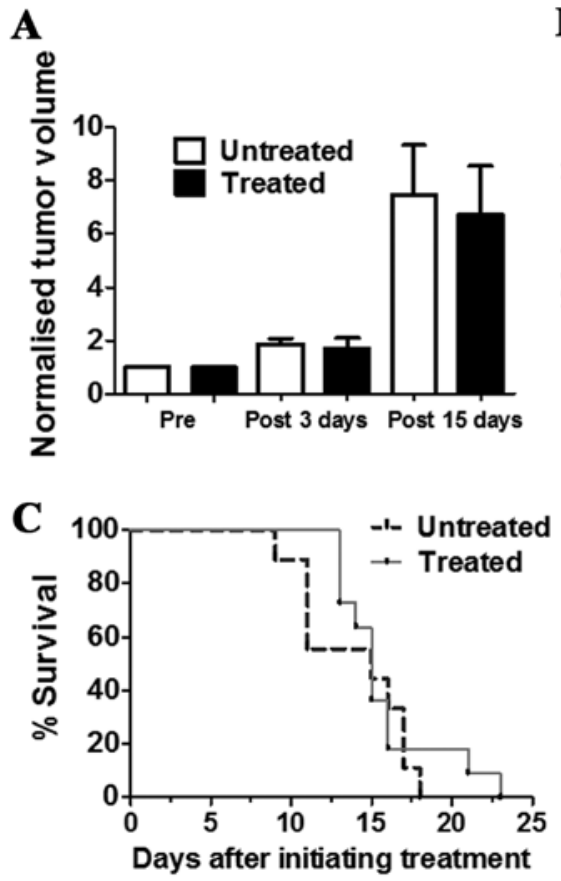

B

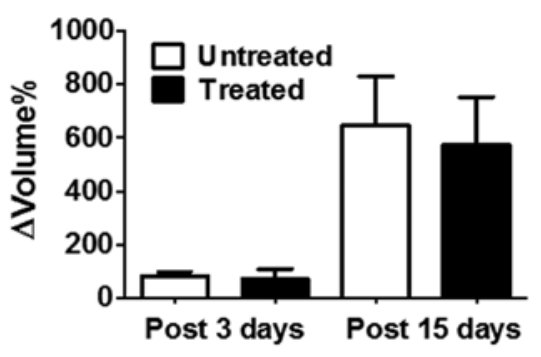

Figure 4. Effect of DCA on tumour growth in vivo. (A) Normalised and (B) percentage changes in volume ( $\Delta$ Volume\%) of TS/A tumour-bearing mice before and after 3 or 15 days of DCA treatment. (C) Mouse survival curve after DCA treatment.

levels measured in the extracellular medium of TS/A cells. In particular, we observed a significant decrease in lactate production following DCA treatment in both normoxic and hypoxic conditions (Figs. 2B and 3B). Moreover, the in vitro anti-glycolytic effect of DCA revealed a strong and significant correlation between $\mathrm{pH}$ and lactate changes in normoxic condition ( $r=-0.98, P=<0.05$, Fig. $2 C$ ), likely reflecting the impaired glycolytic activity that results in a reduced lactate production, hence acidification. A strong correlation was also found for cells treated in hypoxic condition even though not statistically significant $(r=-0.93, P=0.07$, Fig. $3 C)$. Taken together, these data confirmed the in vitro reversal of the glycolytic phenotype following DCA treatment.

DCA does not influence tumour growth and survival. The in vivo antitumour activity of DCA was evaluated by measuring tumour growth in a group of TS/A tumour-bearing BALB/c mice that received drinking water and PBS intraperitoneal injection (untreated) or that were treated with DCA by oral administration and intraperitoneal injection every day for 3 or 15 consecutive days (Fig. 4A). DCA treatment slightly reduced the growth of TS/A breast tumours after three days of treatment $(\Delta$ Volume $\%=70.7 \pm 38.6$ and $83.1 \pm 15.7$, for treated and untreated mice, respectively; $\mathrm{P}>0.05$ ). This limited growth reduction is maintained up to 15 days of DCA treatment $(\Delta$ Volume $\%=571.9 \pm 180.7$ and $646.7 \pm 184.0$, for untreated and treated mice, respectively; $\mathrm{P}>0.05$ ) (Fig. 4B).

The survival study conducted in another group of mice revealed that DCA-treated mice survived slightly longer than the untreated mice (Fig. 4C), despite this difference not being statistically significant. These data suggest that DCA did not influence tumour growth and did not improve mouse survival for the TS/A tumour model.

DCA affects in vivo tumour acidosis and lactate production. A significant $\mathrm{pHe}$ increase was observed for treated mice in comparison to untreated ones after three days of DCA treatment $(\Delta \mathrm{pHe}=+0.10 \pm 0.03$ and $-0.12 \pm 0.03$ for treated 

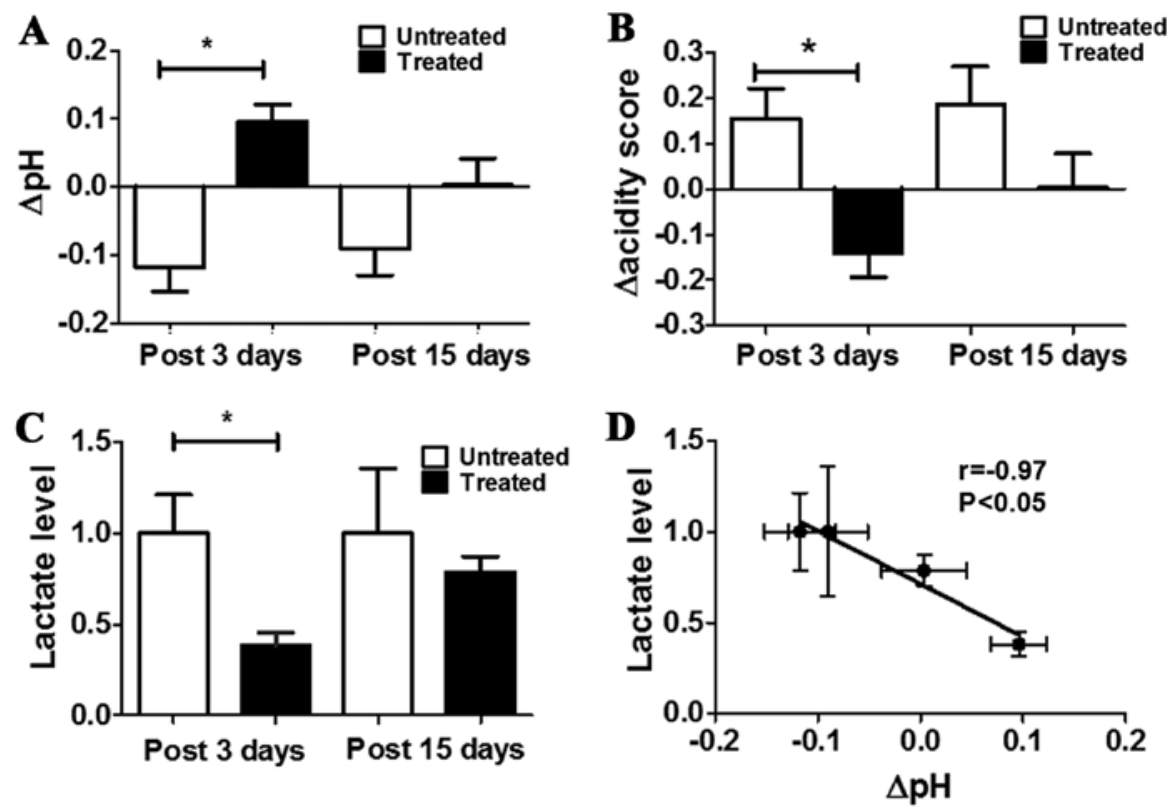

Figure 5. Effect of DCA on extracellular tumour $\mathrm{pH}(\mathrm{pHe})$ and on lactate levels in vivo. Tumour pHe (A) and acidity score (B) changes calculated from TS/A tumour-bearing mice upon DCA treatment after 3 and 15 days, in comparison to before treatment tumour pHe values for untreated and treated mice. (C) Lactate quantification from excised TS/A tumour tissues for untreated and treated mice after 3 and 15 days of DCA treatment. (D) Correlation between changes in tumour $\mathrm{pHe}$ and lactate levels (Pearson's $\mathrm{r}=-0.97,{ }^{*} \mathrm{P}<0.05$ ).

and untreated, respectively, $\mathrm{P}<0.05$, Fig. 5A). The same $\mathrm{pHe}$ variations were maintained also after 15 days of treatment, despite less marked $(\Delta \mathrm{pHe}=+0.004 \pm 0.04$ and $-0.09 \pm 0.04$ for treated and untreated, respectively, Fig. 5A). Representative MRI-CEST pHe images over imposed to anatomical images are shown in Fig. 6 for untreated (Fig. 6A) and treated (Fig. 6B) mice. Following DCA-treatment, an increase of the number of pixels with more neutral pHe values is visible, in contrast to untreated mice at both the investigated time points (i.e. after 3 and 15 days of DCA treatment).

To assess more precisely the heterogeneity of the extracellular $\mathrm{pH}$ distribution inside the tumour region, it was deemed of interest to calculate the acidity score as an index of spatial distribution of acidosis. A marked and statistically significant difference was observed in the changes of the acidity scores between untreated and treated mice after 3 days of treatment $(\Delta$ acidity score $=-0.14 \pm 0.23$ and $+0.15 \pm 0.34$, $\mathrm{P}<0.05$, Fig. 5B). After 15 days a marked difference in $\mathrm{pHe}$ distribution still remains between treated and untreated mice ( $\Delta$ acidity score $=+0.003 \pm 0.24$ and $+0.18 \pm 0.35$ for treated and untreated mice, respectively; $\mathrm{P}>0.05$ ). Representative acidity score maps are shown in Fig. 6C and D for untreated and treated mice, respectively. Upon DCA-treatment, a decrease in the number of pixels clustered at more acidic $\mathrm{pH}$ values (colour coded in red) is well detected after three days of treatment. The MRI-based measurements of tumour extracellular $\mathrm{pH}$ showed that DCA was effective in inhibiting tumour glycolysis in vivo, resulting in a marked decreased acidification of the interstitial space, as observed for the in vitro studies.

Tumour lactate concentration of treated mice was significantly decreased compared with untreated ones (lactate levels in treated mice was ca. three times lower than in untreated mice, $\mathrm{P}=0.0077$ ). No significant variation in tumour lactate levels was observed comparing treated to untreated mice after 15 days (Fig. 5C). A strong and significant inverse correlation was found between lactate levels and changes in tumour $\mathrm{pHe}$ $(r=-0.97, P<0.05$, Fig. 5D). These results suggest that DCA can inhibit the glycolytic activity of TS/A tumours, at least for early time points and that changes in lactate production and extracellular $\mathrm{pH}$ are highly correlated.

\section{Discussion}

High rate of glucose uptake and of lactate production are two distinctive features of metabolically altered tumour cells. DCA is able to revert the glycolytic phenotype through metabolic inhibition of PDK that allows pyruvate to enter into the tricarboxylic acid cycle thus limiting lactate production and in turn, decreasing $\mathrm{H}^{+}$ions pumped out in the extracellular space. Herein, we investigated the effect of DCA on tumour pHe in a breast cancer murine model using a non-invasive MRI-based CEST pH imaging approach.

All the investigated breast cancer cell lines showed a marked reduction in their metabolic capacity and vitality, but their response to DCA was dependent on DCA concentration as well as on the cell line itself, hence indicating different sensitivity. Previous studies in other breast cancer cell lines showed that they were sensitive to DCA (32) but not all to the same extent, indicating a cell line dependency. Sensitivity to DCA may be dependent on several factors, including different expression and/or activity of PDK-PDH isoenzymes (37), or DCA internalization that is dependent on the ability to reach mitochondria matrix (38).

Moreover, evidence confirmed that the DCA effect on cell cycle is also cellular-dependent and studies conducted on glioblastoma, glioma, non-small cell lung cancer and colon rectal cancer cells revealed that DCA treatment at $20 \mathrm{mM}$ 

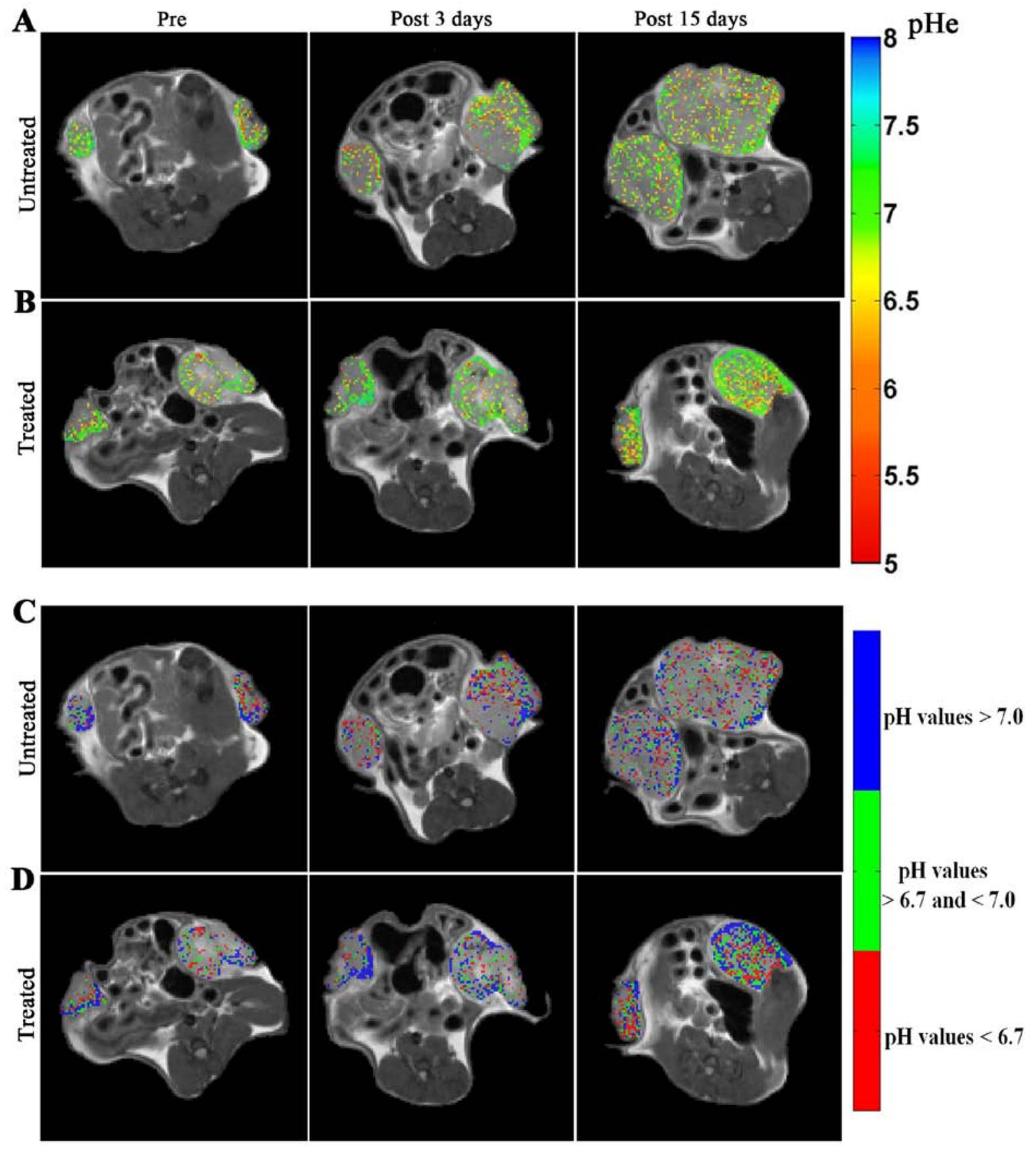

Figure 6. Representative tumour extracellular $\mathrm{pH}$ (pHe, reflecting acidosis) maps for untreated (A) and treated mouse (B) and their corresponding acidity score maps (color-coded as red for pixels showing $\mathrm{pH}$ values $<6.7$; green for $\mathrm{pH}$ values $>6.7$ and $<7$; blue for $\mathrm{pH}$ values $>7.0$ ) for untreated (C) and treated mouse (D) superimposed on anatomical images at baseline (left), 3 days (middle) and 15 days (right) post-DCA treatment. Tumour pHe and acidity score values are shown only within tumour regions for improving clarity.

concentration caused apoptosis and G2 phase cell cycle arrest $(33,34)$. In TS/A cells, $10 \mathrm{mM}$ DCA induced a small increase in $\mathrm{G} 2 / \mathrm{M}$ phase although not statistically significant. Taken together these data indicate that DCA is not a cytotoxic drug but it acts as a metabolic agent.

DCA-induced glycolysis inhibition is expected to reduce lactate production, hence alter extracellular acidification, as already demonstrated in previous in vitro studies by measuring pHe changes $(39,40)$. Within this study, we observed a marked increase of extracellular $\mathrm{pH}$ that was dependent on DCA concentration; moreover, the alkalinisation of $\mathrm{pHe}$ was even more pronounced when TS/A cells were cultured in hypoxic conditions $\left(1 \% \mathrm{O}_{2}\right)$ than in normoxic conditions, simulating a poorly-perfused tumour microenvironment. Our in vivo MRI-based observations reflect similar findings, since we measured a significant increase in tumour pHe as early as three days after DCA-treatment.

Other studies in breast and prostate cell lines showed that lactate production is reduced upon DCA treatment (41-43). We observed that lactate production was reduced following DCA treatment both in vitro, just after $24 \mathrm{~h}$, as well as in vivo, with a marked decrease in lactate levels after three days of treatment. Notably, these changes in lactate levels were highly correlated with changes in $\mathrm{pHe}$ in vitro and the same strong 
correlation was found in vivo, likely reflecting the intertwined dependence between glycolysis, lactate levels and tumour acidosis (Figs. 2C, 3C and 5D).

Although other in vivo studies confirmed the DCA antitumour activity on solid tumours (44), in this study treated mice showed a limited tumour growth reduction following 15 days of treatment and only a slight increase of the survival time was observed as compared to untreated mice. This may be explained considering that DCA alone has a moderate efficiency as chemotherapeutic drug, and its antineoplastic pharmacological effect can be augmented when used in combination with other drugs $(41,45,46)$. Our results are in agreement with these observations, as similar lactate levels were observed in untreated and treated mice after 15 days of treatment. These results parallel those obtained by measuring in vivo tumour $\mathrm{pHe}$, which at 15 days show a reduced difference between treated and untreated mice in terms of pHe changes and of acidity scores. These findings confirm the ability of the proposed non-invasive approach to assess the onset of resistance to DCA, since tumour acidosis returned to almost baseline values after 15 days. This behaviour was confirmed by similar changes in lactate levels. Moreover, the inefficacy of DCA to halt tumour glycolysis after 15 days, as measured by the proposed approach, anticipated the lack of difference in terms of survival times between treated and untreated groups.

In this study, in vivo $\mathrm{pH}$ changes were assessed by MRI-CEST imaging using iopamidol, an MRI-CEST $\mathrm{pH}$-responsive agent able to map pHe and tumour perfusion in the microenvironment in which it is distributed (47-49). Although iopamidol showed a heterogeneous distribution in the tumour region, the application of the ratiometric $\mathrm{pH}$ method allowed obtaining representative $\mathrm{pH}$ maps for the region of interest. To get more insight into the tumour $\mathrm{pHe}$ heterogeneity, we calculated the acidity score that reports on the distribution of pixels clustered on the basis of their relative acidity inside the tumour region. Representative acidity score maps showed an increase in blue pixels during DCA treatment for treated mice (Fig. 6D), reflecting the DCA-induced glycolysis inhibition, hence alkalinisation of tumour pHe, although we cannot exclude that there are other pathways that may contribute to tumour extracellular acidification (50). A similar decrease of tumour acidosis was observed in a xenograft model of B-cell lymphoma upon treatment with metaiodobenzylguanidine by using an analogous pH-responsive CEST agent (51). Of note, also endogenous CEST pH mapping allowed monitoring intracellular acidification following lonidamine or topiramate treatment in orthotopic glioblastoma tumours $(52,53)$. All these results confirm the feasibility of MRI-CEST pH mapping to monitor the response to drugs targeting tumour metabolism.

In conclusion, despite the lack of tumour growth reduction, this study demonstrated that MRI-CEST pH imaging is able to detect the early response to DCA by measuring changes in tumour pHe. These findings correlated well with the observed reduced lactate levels as a consequence of the reversed glycolytic phenotype. These results suggest that MRI-CEST $\mathrm{pH}$ imaging may serve as a useful imaging biomarker for monitoring changes in metabolism following drugs targeting tumour deregulated glycolysis.

\section{Acknowledgements}

Financial support from European Community's Seventh Framework Programme (H2020 GLINT project 667510) is gratefully acknowledged. L.C. was supported by a fellowship from Fondazione Umberto Veronesi.

\section{References}

1. Gerweck LE and Seetharaman K: Cellular $\mathrm{pH}$ gradient in tumor versus normal tissue: Potential exploitation for the treatment of cancer. Cancer Res 56: 1194-1198, 1996.

2. Warburg $\mathrm{O}$, Wind $\mathrm{F}$ and Negelein E: The metabolism of tumors in the body. J Gen Physiol 8: 519-530, 1927.

3. Webb BA, Chimenti M, Jacobson MP and Barber DL: Dysregulated $\mathrm{pH}$ : A perfect storm for cancer progression. Nat Rev Cancer 11: 671-677, 2011.

4. Hashim AI, Zhang X, Wojtkowiak JW, Martinez GV and Gillies RJ: Imaging $\mathrm{pH}$ and metastasis. NMR Biomed 24: 582-591, 2011.

5. Michelakis ED, Webster L and Mackey JR: Dichloroacetate (DCA) as a potential metabolic-targeting therapy for cancer. Br J Cancer 99: 989-994, 2008.

6. McFate T, Mohyeldin A, Lu H, Thakar J, Henriques J, Halim ND, Wu H, Schell MJ, Tsang TM, Teahan O, et al: Pyruvate dehydrogenase complex activity controls metabolic and malignant phenotype in cancer cells. J Biol Chem 283: 22700-22708, 2008.

7. Bonnet S, Archer SL, Allalunis-Turner J, Haromy A, Beaulieu C, Thompson R, Lee CT, Lopaschuk GD, Puttagunta L, Bonnet S, et al: A mitochondria- $\mathrm{K}^{+}$channel axis is suppressed in cancer and its normalization promotes apoptosis and inhibits cancer growth. Cancer Cell 11: 37-51, 2007.

8. De Preter G, Neveu MA, Danhier P, Brisson L, Payen VL, Porporato PE, Jordan BF, Sonveaux P and Gallez B: Inhibition of the pentose phosphate pathway by dichloroacetate unravels a missing link between aerobic glycolysis and cancer cell proliferation. Oncotarget 7: 2910-2920, 2016.

9. Dunbar EM, Coats BS, Shroads AL, Langaee T, Lew A, Forder JR, Shuster JJ, Wagner DA and Stacpoole PW: Phase 1 trial of dichloroacetate (DCA) in adults with recurrent malignant brain tumors. Invest New Drugs 32: 452-464, 2014.

10. Zhang X, Lin Y and Gillies RJ: Tumor $\mathrm{pH}$ and its measurement. J Nucl Med 51: 1167-1170, 2010.

11. Gillies RJ, Liu Z and Bhujwalla Z: ${ }^{31} \mathrm{P}-\mathrm{MRS}$ measurements of extracellular $\mathrm{pH}$ of tumors using 3-aminopropylphosphonate. Am J Physiol 267: C195-C203, 1994.

12. Garcia-Martin ML, Martinez GV, Raghunand N, Sherry AD, Zhang S and Gillies RJ: High resolution $\mathrm{pH}(\mathrm{e})$ imaging of rat glioma using $\mathrm{pH}-d e p e n d e n t$ relaxivity. Magn Reson Med 55: 309-315, 2006 .

13. Gallagher FA, Kettunen MI, Day SE, Hu DE, ArdenkjaerLarsen JH, Zandt R, Jensen PR, Karlsson M, Golman K, Lerche $\mathrm{MH}$, et al: Magnetic resonance imaging of $\mathrm{pH}$ in vivo using hyperpolarized ${ }^{13} \mathrm{C}$-labelled bicarbonate. Nature 453: 940-943, 2008.

14. Serrao EM and Brindle KM: Potential clinical roles for metabolic imaging with hyperpolarized $\left[1-{ }^{13} \mathrm{C}\right]$ pyruvate. Front Oncol 6: 59, 2016.

15. Reineri F, Daniele V, Cavallari E and Aime S: Assessing the transport rate of hyperpolarized pyruvate and lactate from the intra- to the extracellular space. NMR Biomed 29: 1022-1027, 2016.

16. Reineri F, Boi T and Aime S: Parahydrogen induced polarization of ${ }^{13} \mathrm{C}$ carboxylate resonance in acetate and pyruvate. Nat Commun 6: 5858, 2015.

17. Viale A, Reineri F, Dastrù W and Aime S: Hyperpolarized (13) C-pyruvate magnetic resonance imaging in cancer diagnostics. Expert Opin Med Diagn 6: 335-345, 2012.

18. Menzel MI, Farrell EV, Janich MA, Khegai O, Wiesinger F, Nekolla S, Otto AM, Haase A, Schulte RF and Schwaiger M: Multimodal assessment of in vivo metabolism with hyperpolarized $\left[1-{ }^{13} \mathrm{C}\right] \mathrm{MR}$ spectroscopy and $18 \mathrm{~F}-\mathrm{FDG}$ PET imaging in hepatocellular carcinoma tumor-bearing rats. J Nucl Med 54: 1113-1119, 2013.

19. Rivlin M and Navon G: Glucosamine and N-acetyl glucosamine as new CEST MRI agents for molecular imaging of tumors. Sci Rep 6: 32648, 2016. 
20. Xu X, Chan KW, Knutsson L, Artemov D, Xu J, Liu G, Kato Y, Lal B, Laterra J, McMahon MT, et al: Dynamic glucose enhanced (DGE) MRI for combined imaging of blood-brain barrier break down and increased blood volume in brain cancer. Magn Reson Med 74: 1556-1563, 2015

21. Rivlin M, Tsarfaty I and Navon G: Functional molecular imaging of tumors by chemical exchange saturation transfer MRI of 3-O-Methyl-D-glucose. Magn Reson Med 72: 1375-1380, 2014.

22. Walker-Samuel S, Ramasawmy R, Torrealdea F, Rega M, Rajkumar V, Johnson SP, Richardson S, Gonçalves M, Parkes HG, Arstad E, et al: In vivo imaging of glucose uptake and metabolism in tumors. Nat Med 19: 1067-1072, 2013.

23. Hingorani DV, Bernstein AS and Pagel MD: A review of responsive MRI contrast agents: 2005-2014. Contrast Media Mol Imaging 10: 245-265, 2015

24. Longo DL, Dastrù W, Digilio G, Keupp J, Langereis $\mathrm{S}$, Lanzardo S, Prestigio S, Steinbach O, Terreno E, Uggeri F, et al: Iopamidol as a responsive MRI-chemical exchange saturation transfer contrast agent for $\mathrm{pH}$ mapping of kidneys: In vivo studies in mice at 7 T. Magn Reson Med 65: 202-211, 2011.

25. Longo DL, Busato A, Lanzardo S, Antico F and Aime S: Imaging the $\mathrm{pH}$ evolution of an acute kidney injury model by means of iopamidol, a MRI-CEST pH-responsive contrast agent. Magn Reson Med 70: 859-864, 2013.

26. Chen LQ, Howison CM, Jeffery JJ, Robey IF, Kuo PH and Pagel MD: Evaluations of extracellular $\mathrm{pH}$ within in vivo tumors using acidoCEST MRI. Magn Reson Med 72: 1408-1417, 2014

27. Moon BF, Jones KM, Chen LQ, Liu P, Randtke EA, Howison CM and Pagel MD: A comparison of iopromide and iopamidol, two acidoCEST MRI contrast media that measure tumor extracellular pH. Contrast Media Mol Imaging 10: 446-455, 2015.

28. Yang X, Song X, Ray Banerjee S, Li Y, Byun Y, Liu G Bhujwalla ZM, Pomper MG and McMahon MT: Developing imidazoles as CEST MRI pH sensors. Contrast Media Mol Imaging 11: 304-312, 2016.

29. Longo DL, Bartoli A, Consolino L, Bardini P, Arena F, Schwaiger $M$ and Aime S: In vivo imaging of tumor metabolism and acidosis by combining PET and MRI-CEST pH imaging. Cancer Res 76: 6463-6470, 2016.

30. Nanni P, de Giovanni C, Lollini PL, Nicoletti G and Prodi G: TS/A: A new metastasizing cell line from a BALB/c spontaneous mammary adenocarcinoma. Clin Exp Metastasis 1: 373-380, 1983.

31. Lanzardo S, Conti L, Rooke R, Ruiu R, Accart N, Bolli E, Arigoni M, Macagno M, Barrera G, Pizzimenti S, et al: Immunotargeting of antigen xCT attenuates stem-like cell behavior and metastatic progression in breast cancer. Cancer Res 76: 62-72, 2016.

32. Sun RC, Fadia M, Dahlstrom JE, Parish CR, Board PG and Blackburn AC: Reversal of the glycolytic phenotype by dichloroacetate inhibits metastatic breast cancer cell growth in vitro and in vivo. Breast Cancer Res Treat 120: 253-260, 2010.

33. Duan Y, Zhao X, Ren W, Wang X, Yu KF, Li D, Zhang X and Zhang Q: Antitumor activity of dichloroacetate on C6 glioma cell: In vitro and in vivo evaluation. Onco Targets Ther 6: 189-198, 2013

34. Takahashi M, Watari E and Takahashi H: Dichloroacetate induces cell cycle arrest in human glioblastoma cells persistently infected with measles virus: A way for controlling viral persistent infection. Antiviral Res 113: 107-110, 2015.

35. Allen KT, Chin-Sinex H, DeLuca T, Pomerening JR, Sherer J, Watkins JB III, Foley J, Jesseph JM and Mendonca MS: Dichloroacetate alters Warburg metabolism, inhibits cell growth, and increases the X-ray sensitivity of human A549 and H1299 NSC lung cancer cells. Free Radic Biol Med 89: 263-273, 2015.

36. Madhok BM, Yeluri S, Perry SL, Hughes TA and Jayne DG: Dichloroacetate induces apoptosis and cell-cycle arrest in colorectal cancer cells. Br J Cancer 102: 1746-1752, 2010.
37. Bowker-Kinley MM, Davis WI, Wu P, Harris RA and Popov KM Evidence for existence of tissue-specific regulation of the mammalian pyruvate dehydrogenase complex. Biochem J 329: 191-196, 1998.

38. Babu E, Ramachandran S, CoothanKandaswamy V, Elangovan S, Prasad PD, Ganapathy V and Thangaraju M: Role of SLC5A8, a plasma membrane transporter and a tumor suppressor, in the antitumor activity of dichloroacetate. Oncogene 30: 4026-4037, 2011.

39. Haugrud AB, Zhuang Y, Coppock JD and Miskimins WK Dichloroacetate enhances apoptotic cell death via oxidative damage and attenuates lactate production in metformin-treated breast cancer cells. Breast Cancer Res Treat 147: 539-550, 2014.

40. Kumar A, Kant S and Singh SM: Novel molecular mechanisms of antitumor action of dichloroacetate against $\mathrm{T}$ cell lymphoma: Implication of altered glucose metabolism, $\mathrm{pH}$ homeostasis and cell survival regulation. Chem Biol Interact 199: 29-37, 2012.

41. Robey IF and Martin NK: Bicarbonate and dichloroacetate: Evaluating $\mathrm{pH}$ altering therapies in a mouse model for metastatic breast cancer. BMC Cancer 11: 235, 2011

42. Xintaropoulou C, Ward C, Wise A, Marston H, Turnbull A and Langdon SP: A comparative analysis of inhibitors of the glycolysis pathway in breast and ovarian cancer cell line models. Oncotarget 6: 25677-25695, 2015.

43. Kailavasan M, Rehman I, Reynolds S, Bucur A, Tozer G and Paley M: NMR-based evaluation of the metabolic profile and response to dichloroacetate of human prostate cancer cells. NMR Biomed 27: 610-616, 2014.

44. Kinnaird A, Dromparis P, Saleme B, Gurtu V, Watson K, Paulin R, Zervopoulos S, Stenson T, Sutendra G, Pink DB, et al: Metabolic modulation of clear-cell renal cell carcinoma with dichloroacetate, an inhibitor of pyruvate dehydrogenase kinase. Eur Urol 69: 734-744, 2016.

45. Sanchez WY, McGee SL, Connor T, Mottram B, Wilkinson A, Whitehead JP, Vuckovic S and Catley L: Dichloroacetate inhibits aerobic glycolysis in multiple myeloma cells and increases sensitivity to bortezomib. Br J Cancer 108: 1624-1633, 2013.

46. Xie J, Wang BS, Yu DH, Lu Q, Ma J, Qi H, Fang C and Chen HZ: Dichloroacetate shifts the metabolism from glycolysis to glucose oxidation and exhibits synergistic growth inhibition with cisplatin in HeLa cells. Int J Oncol 38: 409-417, 2011.

47. Longo DL, Sun PZ, Consolino L, Michelotti FC, Uggeri F and Aime S: A general MRI-CEST ratiometric approach for $\mathrm{pH}$ imaging: Demonstration of in vivo $\mathrm{pH}$ mapping with iobitridol. J Am Chem Soc 136: 14333-14336, 2014.

48. Longo DL, Michelotti F, Consolino L, Bardini P, Digilio G, Xiao G, Sun PZ and Aime S: In vitro and in vivo assessment of nonionic iodinated radiographic molecules as chemical exchange saturation transfer magnetic resonance imaging tumor perfusion agents. Invest Radiol 51: 155-162, 2016.

49. Anemone A, Consolino L and Longo DL: MRI-CEST assessment of tumour perfusion using X-ray iodinated agents: Comparison with a conventional Gd-based agent. Eur Radiol 27: 2170-2179, 2017.

50. Kato Y, Ozawa S, Miyamoto C, Maehata Y, Suzuki A, Maeda T and Baba Y: Acidic extracellular microenvironment and cancer. Cancer Cell Int 13: 89, 2013.

51. Chen LQ, Howison CM, Spier C, Stopeck AT, Malm SW, Pagel MD and Baker AF: Assessment of carbonic anhydrase IX expression and extracellular $\mathrm{pH}$ in B-cell lymphoma cell line models. Leuk Lymphoma 56: 1432-1439, 2015.

52. McVicar N, Li AX, Meakin SO and Bartha R: Imaging chemical exchange saturation transfer (CEST) effects following tumorselective acidification using lonidamine. NMR Biomed 28: 566-575, 2015

53. Marathe K, McVicar N, Li A, Bellyou M, Meakin S and Bartha R: Topiramate induces acute intracellular acidification in glioblastoma. J Neurooncol 130: 465-472, 2016. 